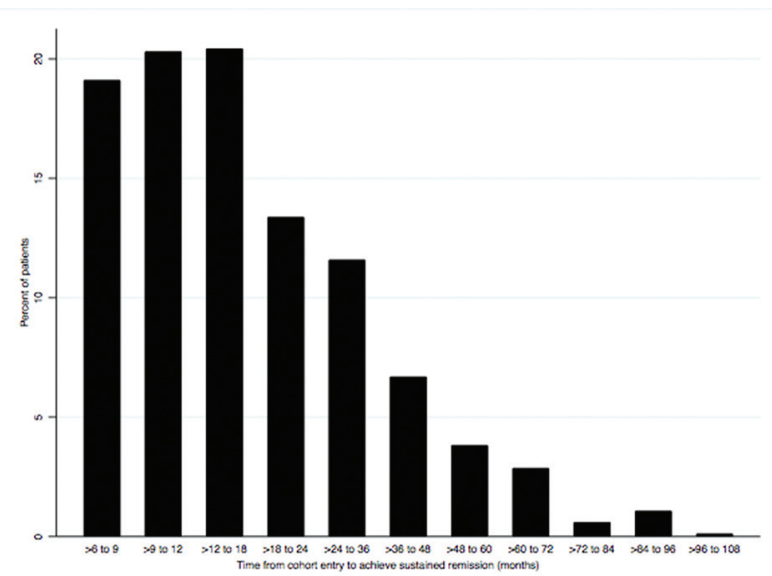

Abstract THU0153 - Figure 1. Bar graph demonstrating distribution of time (in months) to achieve first sustained remission

Disclosure of Interests: Maria Powell: None declared, Vivian Bykerk Grant/research support from: Mallinckrodt, BMS, Crescendo Biosciences, Sanofi/Regeneron., Consultant for: Amgen, Pfizer, UCB, Scipher, Sanofi/ Genzyme/Regeneron, Orit Schieir: None declared, Janet Pope Consultant for: Eli Lilly and Company, Susan J. Bartlett Consultant for: Pfizer, UCB, Lilly, Novartis, Merck, Jansen, Abbvie, Louis Bessette Grant/research support from: Amgen, BMS, Janssen, Roche, UCB, AbbVie, Pfizer, Merck, Celgene, Sanofi, Lilly, Novartis, Consultant for: Amgen, BMS, Janssen, Roche, UCB, AbbVie, Pfizer, Merck, Celgene, Sanofi, Lilly, Novartis, Speakers bureau: Amgen, BMS, Janssen, Roche, UCB, AbbVie, Pfizer, Merck, Celgene, Sanofi, Lilly, Novartis, Gilles Boire Grant/research support from: Investigator-initiated studies: Amgen, Abbvie, BMS, Eli Lilly, Merck, Novartis, Pfizer, Consultant for: Advisory boards: Amgen, BMS, Celgene, Eli Lilly, Pfizer, Speakers bureau: Merck, BMS, Pfizer, CArol Hitchon Grant/research support from: Pfizer, UCB (unrelated studies), Edward Keystone Grant/research support from: AbbVie, Amgen, Bristol-Myers Squibb, F. Hoffmann-La Roche Inc, Gilead, Janssen Inc, Lilly Pharmaceuticals, Pfizer Pharmaceuticals, Sanofi-Aventis, Consultant for: AbbVie, Amgen, AstraZeneca Pharma, Biotest, Bristol-Myers Squibb Company, Celltrion, Crescendo Bioscience, F. Hoffmann-La Roche Inc, Genentech Inc, Gilead, Janssen Inc, Lilly

Pharmaceuticals, Merck, Pfizer Pharmaceuticals, Sandoz, UCB., Speakers bureau: Amgen, AbbVie, Bristol-Myers Squibb Canada, F. Hoffmann-La Roche Inc., Janssen Inc., Merck, Pfizer Pharmaceuticals, Sanofi Genzyme, UCB, Carter Thorne Grant/research support from: Investigator-initiated studies: Amgen, Pfizer. RCTs: Abbvie, Celgene, CaREBiodam, Novartis, Pfizer, Consultant for: Advisory board: Abbvie, Amgen, Celgene, Lilly, Medexus/Medac, Merck, Novartis, Pfizer, Sanofi. Consultant: Abbvie, Centocor, Janssen, Lilly, Medexus/Medac, Pfizer, Speakers bureau: Medexus/Medac, Diane Tin: None declared, Marie-France Valois: None declared, Glen Hazlewood : None declared

DOI: 10.1136/annrheumdis-2019-eular.2320

\section{THU0154 HIGH RESOLUTION COMPUTED TOMOGRAPHY (HRCT) OF THE LUNG IN PATIENTS WITH RHEUMATOID ARTHRITIS: PREVALENCE OF INTERSTITIAL LUNG DISEASE INVOLVEMENT AND DETERMINANTS OF ABNORMALITIES}

Fausto Salaffi ${ }^{1}$, Marina Carotti ${ }^{2}$, Marco DI Carlo ${ }^{1}$, Marika Tardella ${ }^{3}$, Andrea Giovagnoni ${ }^{2}{ }^{1}$ Dipartimento di Scienze Cliniche e Molecolari - Università Politecnica delle Marche, Jesi (AN), Italy; ${ }^{2}$ Radiology Department - Università Politecnica delle Marche, Ancona, Italy, ${ }^{3}$ Rheumatological Clinic, Dipartimento di Scienze Cliniche e Molecolari - Università Politecnica delle Marche, Jesi (AN), Italy

Background: Interstitial lung disease (ILD) causes significant morbidity and mortality in patients with rheumatoid arthritis (RA). An international consensus about the identification of a subgroup of RA-patients with an high risk to develop ILD is still lacking.

Objectives: To assess: (a) the prevalence of ILD involvement in RA on high resolution computed tomography (HRCT) scan; (b) the relationships between pulmonary function tests (PTFs), patient-centred measures and ILD, (c) the potential risk factors that contribute to ILD in RA-patients.
Methods: We retrospectively evaluated the data of RA patients afferent to an italian rheumatological center from $1 / 1 / 2014$ to $30 / 6 / 2018$. We extrapolated clinical (age, gender, age at onset the RA), laboratoristic [rheumatoid factor (RF) and anti-citrullinated protein antibodies (ACPAs)] respiratory functional data [forced vital capacity (FVC) and single-breath diffusing capacity for carbon monoxide (DLco)], patient-centred measures of dyspnea (PCMD) (modified Borg Dyspnea Index and VAS for breathing), health assessment questionnaire-disability index (HAQ-DI), and HRCT. HRCT abnormalities were scored using a conventional visual reader-based score $(\mathrm{CoVR})(1)$ and a computer-aided method $(\mathrm{CaM})(2)$. The relationships among the two HRCT scores, PFTs and PCMD were calculated using Pearson's correlation. The AUC-ROC curve was calculated to determinate the discriminative performance of measures between patients with and without ILD. Multivariate regression model was used to assess the strength of association between ILD and RA features.

Results: 151 patients with RA were included (45 males and 106 females, mean age of $53.4 \pm 7.6$ years). We identified ILD in 29 of 151 patients $(19.2 \%)$. Usual interstitial pneumonia was the most common pattern on HRCT. Patients with ILD were older $(p<0.01)$, their age at RA-onset and HAQ-DI were higher (respectivelly with $\mathrm{p}<0.01$ and $\mathrm{p}<0.05$ ) than patients without RA-ILD. RF positivity and titer were similar in the two groups whereas ACPA positivity and titre were higher in ILD group $(p=0.02)$ Extent and severity of ILD, total CoVR and CaM score correlated closely with DLco and PCMD (both with $\mathrm{p}<0.0001$ ) A reduced DLco was the most sensitive test to predict the presence of ILD on HRCT (AUC-ROC $0.811 \pm 0.037)$. Multivariate analysis showed that older age $(p<0.0001)$, age at RA onset, $(p=0.025)$, APCA titers $(p=0.004)$ and smoking habit $(p=0.008)$ were independent explanatory variables of HRCT damage. Conclusion: ILD is a frequent feature of RA. RA-ILD is associated with age, age at RA-onset, smoking habit, and ACPA titer. DLco seems the most sensitive measure to predict ILD on HRCT scan, followed by PCMD.

\section{REFERENCES :}

1 Warrick JH, Bhalla M, Schabel SI, Silver RM. High resolution computed tomography in early scleroderma lung disease. J Rheumatol. 1991; 18 (10):1520-8.

2 Shin KE, Chung MJ, Jung MP, Choe BK, Lee KS. Quantitative computed tomographic indexes in diffuse interstitial lung disease: correlation with physiologic tests and computed tomography visual scores. J Comput Assist Tomogr. 2011; 35(2):266-27

Disclosure of Interests: Fausto Salaffi Grant/research support from: Abbvie, Roche, Novartis, BMS, Pfizer, Sanofi, Speakers bureau: Abbvie, Roche, Novartis, Pfizer, Sanofi, BMS, marina carotti Speakers bureau: abbvie pfizer novartis roche bms sanofi, Marco Di Carlo: None declared Marika Tardella: None declared, Andrea Giovagnoni: None declared DOI: 10.1136/annrheumdis-2019-eular.7317

\section{THU0155 PATIENT ADHERENCE WITH A SMARTPHONE APP FOR DISEASE MONITORING IN RHEUMATOID ARTHRITIS}

Daniel Solomon ${ }^{1}$, Fengxin Lu ${ }^{1}$, Chang $\mathrm{Xu}^{1}$, Joshua Colls ${ }^{1}$, Dong Hyun Suh ${ }^{1}$, Meredith Murray ${ }^{1}$, Cassandra Corrigan', Yvonne Lee ${ }^{1} .{ }^{1}$ Brigham and Women's Hospital, Rheumatology, Boston, United States of America; ${ }^{2}$ Northwestern Medical Center, Rheumatology, Chicago, United States of America

Background: Patients increasingly are asking for tools to improve selfmanagement. Electronic patient reported outcomes (ePROs) transmitted digitally allow patients to both communicate with their clinicians between visits and help track their own disease activity. While several tools have been developed in rheumatology, few data have been reported regarding patient adherence.

Objectives: To examine patient adherence to a smartphone app for rheumatoid arthritis (RAapp).

Methods: We developed a smartphone app to deliver daily disease assessments to patients with RA (RAapp). The app was tested as part of a randomized controlled trial examining the potential clinical benefits of RAapp compared to a wait-list control. These analyses focus only on the adherence of patients who received RAapp and completed the 6-month trial. We recruited RA patients from the rheumatology practice at a large academic medical center in the US. Patients with at least 6weeks of stable DMARD use who were at least 18years of age were required to give written informed consent, be fluent in English, and have a smartphone with an iOS or android operating system. RAapp was downloaded by patients through a password protected link on to the patient's phone after consent. Patient's received daily notifications regarding disease 